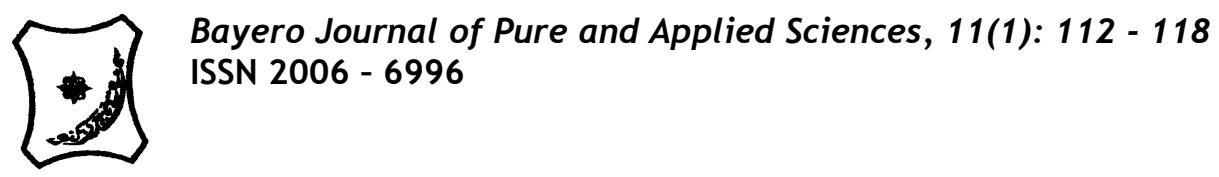

\title{
PARASITOLOGICAL STUDY AND CHANGES IN LEVEL OF SOME SERUM ENZYMES IN KANO BROWN GOATS EXPERIMENTALLY INFECTED WITH Trypanosoma evansi
}

\author{
${ }^{* 1}$ Gumel, M.A. ${ }^{2}$ Oyeyi, T.I. and ${ }^{3}$ Qadir, M. A. \\ 1 Department of Animal Health and Production \\ Binyaminu Usman Polytechnic Hadejia, Jigawa State, Nigeria \\ 2 Department of Biological Sciences, Bayero University, Kano, Kano State, Nigeria \\ 3 Department of Zoological Sciences, Modibbo Adama University of Technology, \\ Adamawa State, Nigeria \\ * Corresponding author: 08035950120; mag370245@gmail.com.
}

\begin{abstract}
Trypanosomosis is a vector borne protozoan disease that is caused by varied members of the genus, Trypanosoma which affect different species of domestic and wild animals including humans. The disease processprovokes alterations in serum enzymes activities in the affected host. This study aimed at investigating the parasitological effects and changes in levels of some serum enzymes activities in Kano brown goats following experimental infection with $T$. evansi originally isolated from naturally infected camels at Maigatari. Infection was through the jugular veins of the experimental subjects ( 3 infected and2uninfected controls) at dose rate of $2.0 \times 10^{6} / \mathrm{ml}$. The period of study spanned 145 days. Sequel to the infection, infected goats developed clinical trypanosomosis and parasites were detected in the peripheral blood of all infected animals at varied prepatent period between 3 and 7 days post infection (DPI). First peak of mean parasitaemia wave was at $9 \mathrm{DPI}$ and second at $14 \mathrm{DPI}$ and death was recorded on the 70 and 133 DPI respectively among the infected group. After $84 \mathrm{DPI}$, no parasite could be detected and control subjects remained aparasitaemic throughout the experimental period. For serum enzymes, alanine aminotransferase (ALT) and aspartate aminotransferase (AST), there was significant $(P<$ $0.05)$ elevation in the infected subjects. The study showedT. evansi isolate caused infection caused changes in the activities of serum enzymes under study.
\end{abstract}

Key words: Experimental infection, Kano brown goats, serum enzymes, Trypanosomosis, Trypanosoma evansi.

\section{INTRODUCTION}

Trypanosoma evansi is a protozoan parasite responsible for a disease called 'surra' which is mechanically and cyclically transmitted by biting flies (Desquesneset al., 2013). It is the most widely spread trypanosome globally and is pathogenic to its host (Hoare, 1872). Furthermore, this parasite has the greatest and widest range of host thus positioned within the spectrum of most important animal health problem in sub-Saharan Africa (Teweriet al., 2013).

On clinical perspective, the disease manifests itself by weakness, fever, anasarca, ataxia, paralysis of the hindquarter and death (Yadevet al., 2016). Despite T. evansi is a primary parasite of camel, there is likelihood that small ruminants herded together with camels especially Kano brown goats may become infected with the parasite and may serve as reservoir host for the agent.

Kano brown goats contributes a great proportion of the goat's population in Nigeria, and play a significant role in furnishing animal's protein to teaming Nigerian population, and is a veritable tool for the alleviation of poverty in the dry ecozones of the country (Olafadechan and Adebayo, 2016).

Notwithstanding the socio-economic contributions of Kano brown goats to Nigerian food security, the breed has received little attention generally, and in trypanosomosis studies specifically (Finangwaiet al., 2018). Therefore, the study aimed at investigating parasitological and changes in levels of some serum enzymes activities following experimental infection with $T$. evansi in Kano brown goats.

\section{MATERIALS AND METHODS}

Study Site

The study was conducted at the Animal Complex, Department of Animal Health and Production, Binyaminu Usman Polytechnic Hadejia, Jigawa State, Nigeria. 
Hadejia lies between $10^{\circ} 36^{\prime} \mathrm{E}$ Longitude and $12^{\circ}$ $30 \mathrm{~N}$ Latitude. The vegetation and climate of the area is influenced by both equatorial maritime and the tropical continental air masses. The daily maximum and minimum temperature are $31^{\circ} \mathrm{C}$ and $19^{\circ} \mathrm{C}$ respectively. The mean relative humidity can be as high as $80 \%$ in the month of August and low as $15 \%$ in December (TNFD, 2011).

Donor Rats and Isolation of $T$. evansi

Parasites used for the experiment were obtained from naturally infected camels at Maigatari, Jigawa State, Nigeria (plate 1). Ten albino rats were obtained from the Department of Biological Sciences, BUK. They were inoculated intraperitoneally (I.P.) with $0.5 \mathrm{ml}$ of the infected blood in ethylene diaminetetra acetic acid (EDTA) containing 3 - 5 Tryps/field using insulin syringe to clone and transport to experimental site(plate 2).

Experimental Goats

Five apparently healthy matured Kano brown goats of both sexes ( 3 males and 2 females) aged 3 - 4 years were purchased from Hadejia Animal Market and were transported to the experimental site. On arrival, they were ear tagged and physically examined for ectoparasites, screened for haemoparasites using wet - mount, thin smear and helminthes by floatation and sedimentation techniques. They were accommodated in fly-proof pen and allowed to acclimatize for four weeks as a conditioning process. Experimental animals were dewormed with albendazole orally at therapeutic dose of $20 \mathrm{mg} / \mathrm{kg}$ body weight. They were fed with groundnut hay, grain offal (dusa) and Digitaria hay, water and saltlick adlibitum. Experimental Goats and Infection with $T$. evansi

Experimental animals were randomly divided into 2 groups (A and $B$ ), Group $A$ (the experimental group) consisted three (designated1, 2 and 3) while group B two (designated 4 and5)(control) goats respectively. The two groups were treated as follows. Group A was experimentally infected while group B served as uninfected control. Fifteen days before infection (DBI), they were closely monitored for clinical signs of illness. At the end of the sixth week, the experimental goats (group A) were challenged via the jugular vein with $2.0 \mathrm{ml}$ of the standard inoculum (diluted infected blood)(Plate 3 ), each animal receiving $2.0 \times 10^{6} \mathrm{~T}$. evansi as quantified using Neubauerheamcytometer (Petena, 1963) with grams iodine as diluent. The control (group B) was left uninfected (Plate 3).

\section{Blood Collection}

Experimental animals were bled from the jugular vein daily from 15 days before infection (DBI) to 14 days post infection (DBI) and after this period, weekly up to 145 days between the hour of 7.00 and 9.00am (Ogbejaet al., 2011). Whole blood was collected into a sterilized glass tubes containing ethylene diamine tetra acetic acid (EDTA) for parasitological and other glass tubes without anticoagulant for serum biochemistry. Blood samples for serum assay were centrifuged for 15 minutes at $2000 \mathrm{rpm}$, separated and freeze stored at $-20^{\circ} \mathrm{C}$.

Parasitological Method

Trypanosoma evansi (Plate 4) was detected in peripheral blood by standard trypanosome detection methods (STDM) Wet blood film, thick blood film, thin blood film and concentration method using haematocrit concentration technique (HCT) as described by Urquahartet al. (1996).

\section{Biochemical Techniques}

Serum was analyzed for the concentration of alanine amino transferase(ALT) and aspartate aminotransferase (AST) by commercial kids (Randox Laboratory Ltd).

\section{Statistical Analysis}

The data obtained in this study were subjected to statistical analysis by student t-test using statistical package of social sciences (SPSS) updated version 15. Data are presented as mean \pm standard error of mean (SEM) as described by Gomez and Gomez (1984).

\section{RESULTS}

Sequel to the experimental infection of the study animals with $T$. evansi Maigatari isolate, parasites were detected in the peripheral blood of all infected goats at different prepatent period between 3 and 7 days post infection(DPI). Mean parasitaemia peaks were observed between 3 and 84 DPI. There were fluctuations in the level of parasitaemia in each of the infected subjects. First peak of mean parasitaemia wave was at $9 \mathrm{DPI}$ and second at $14 \mathrm{DPI}($ Table 1) (Fig.1). Thereafter, a period of low mean parasitaemia were observed except at 56 and $63 \mathrm{DPI}$. Death was recorded in the $10^{\text {th }}$ week post infection. After $84 \mathrm{DPI}$, no parasite could be detected in the blood of the infected subjects (Fig.1). Control subjects remained aparasitaemic throughout the experimental period. The serum enzymes, ALT and AST mean activity values were significantly $(\mathrm{P}<0.05)$ elevated in the infected subjects than in the uninfected group( Table 2)( Fig. 2 and 3). 


\section{DISCUSSION}

From the study, experimental infection of Kano brown goat with Maigatari isolate of $T$. evansi caused disease with incubation period of between 3 and 7 days. This is concurs with findings of Youssif(2000) Shehuet al.(2010) and Yadavet al.(2016). However, Auduet al.(1999) reported shorterincubation period in Yankasa sheep. Mean parasitaemia peaks were observed between 3 and $34 \mathrm{DPI}$ and death were recorded on $10^{\text {th }}$ week DPI. Youssif(2000) studied parasitaemia in $T$. evansi infected goats and the parasitaemia reached maximum on day seven, death on day five post infection. However, death was recorded after 33-49 days as reported by Daganchewet al. (2015) in a work in young zebu cattle. Serum enzymes, ALT and AST mean activity values increased in the infected subjects. The rise in activities these enzymes in goats was reported by Kadimaet al.(2000), Youssifet al.(2008) and Takeedet al (2011). Steven and Michael (2000) mentioned AST is the common marker of hepatocyte and muscle damage. Haemolysis and other processes also increase serum AST. Thus, increase activities of both enzymes indicates pathological effect on the liver (Cheesbrough, 2016;Desquesneset al., 2013)

Table 1: Estimated mean parasitaemia per mililitre of blood using the method of Petana (1963) in $T$. evansi experimentally infected Kano brown goats

Days Post Infection Infected Group Parasitaemia/ml

$\begin{array}{ll}7 & 2.8 \times 10^{4} \\ 14 & 1.5 \times 10^{5} \\ 21 & 1.3 \times 10^{5} \\ 28 & 2.8 \times 10^{4} \\ 35 & 2.5 \times 10^{4} \\ 42 & 2.0 \times 10^{4} \\ 49 & 3.0 \times 10^{4} \\ 56 & 4.2 \times 10^{4} \\ 63 & 4.0 \times 10^{4} \\ 70 & 3.3 \times 10^{4} \\ 77 & 1.8 \times 10^{3} \\ 84 & 5.0 \times 10^{3}\end{array}$

Table 2: Mean serum values of some enzymes in $T$. evansi experientially infected and uninfected Kano brown goats

\begin{tabular}{lccc}
\hline Parameter & $\begin{array}{c}\text { Uninfected Group } \\
(\mathrm{n}=5)\end{array}$ & Infected Group $(\mathrm{n}=5)$ & $\mathrm{P}$ - value \\
\hline AST & $56.6 \pm 2.03$ & $64.9 \pm 1.11$ & 0.0096 \\
ALT & $20.8 \pm 0.61$ & $23.3 \pm 0.55$ & 0.0305 \\
\hline
\end{tabular}

$\mathrm{P}$ value of 0.05 or lower was considered to be significant. 


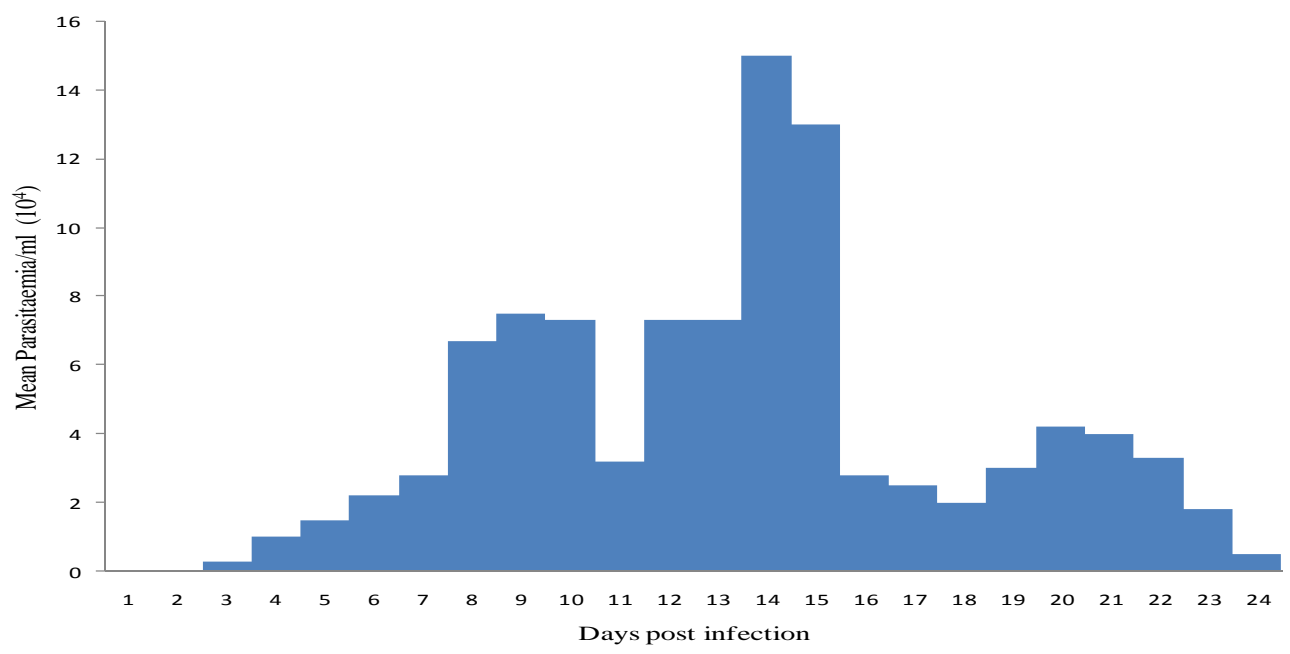

Fig. 1: Post infection mean daily parasitaemia of Kano brown goats experimentally infected with Maigatari isolate of T. evansi

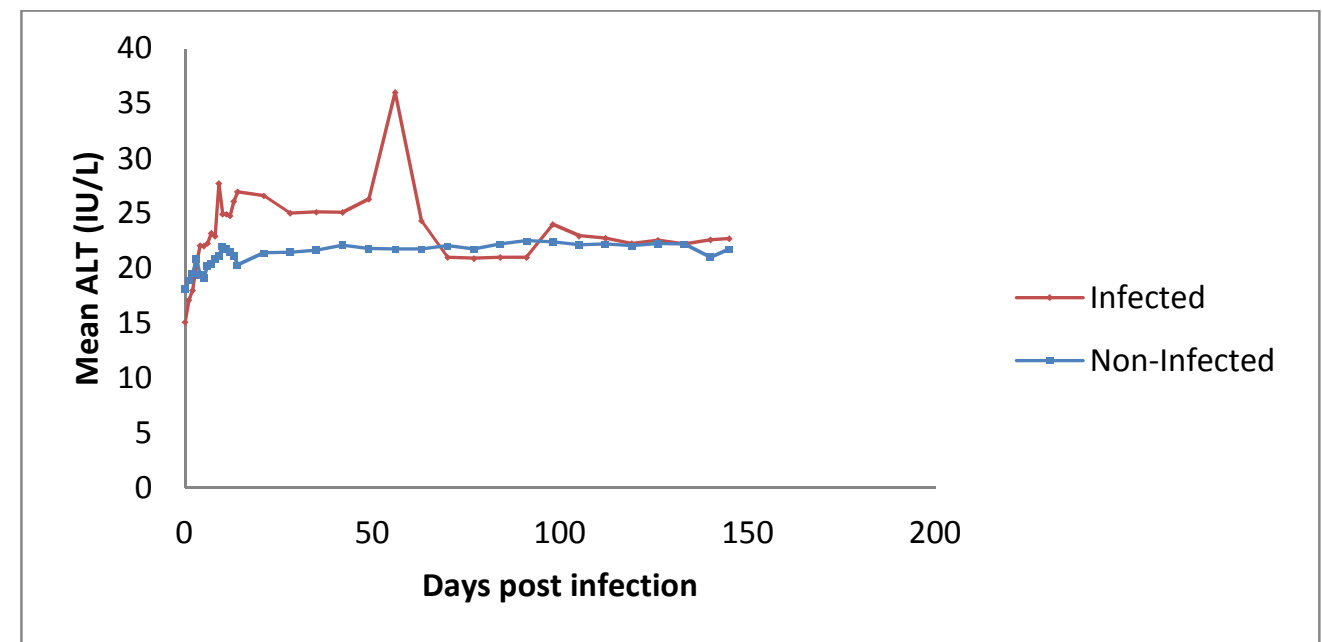

Fig. 2: Post infection mean values of alanine aminotransferase (ALT) of Kano brown goats experimentally infected with Maigatari isolate of T. evansi and control

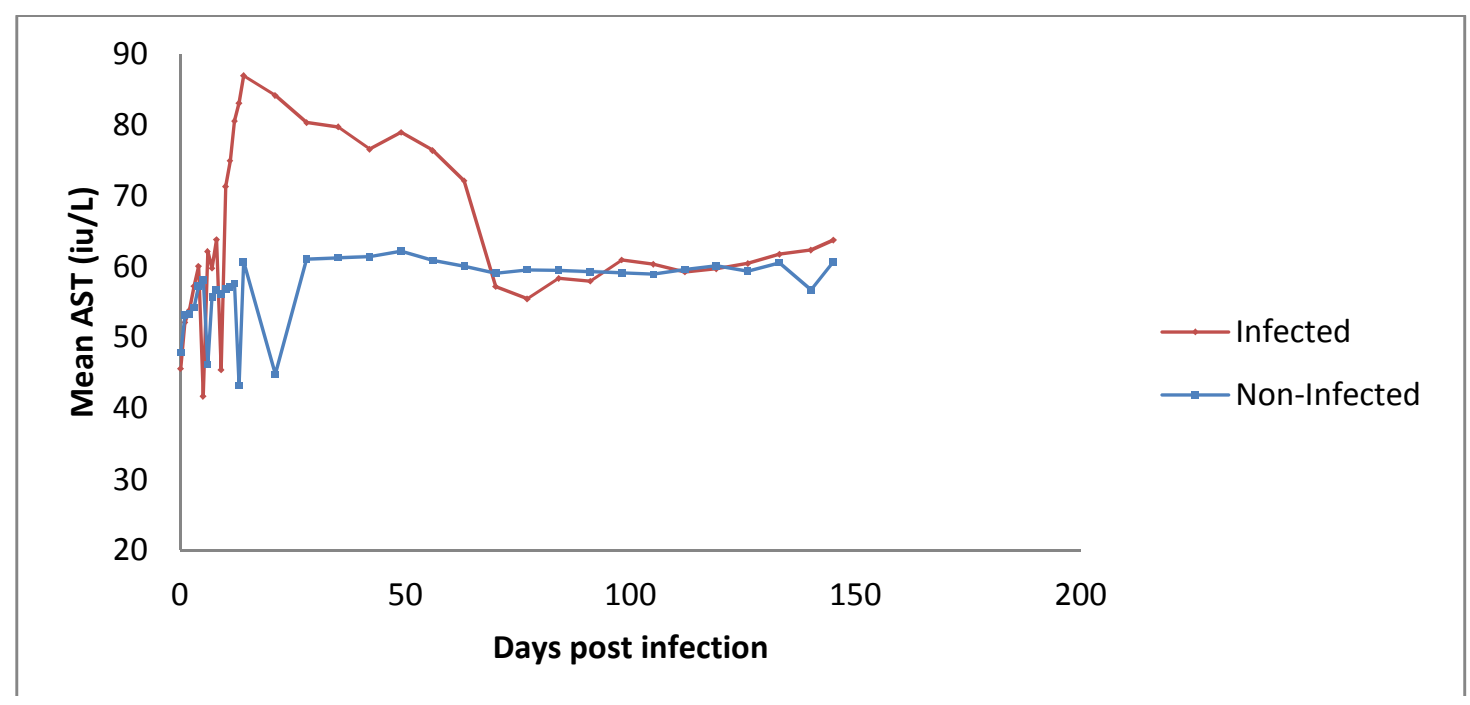

Fig. 3: Post infection mean values of Aspartate aminotransferase (AST) of Kano brown goats experimentally infected with Maigatari isolate of T. evansi and control 




Plate 1: Bleeding from Mammary Vein of Camel

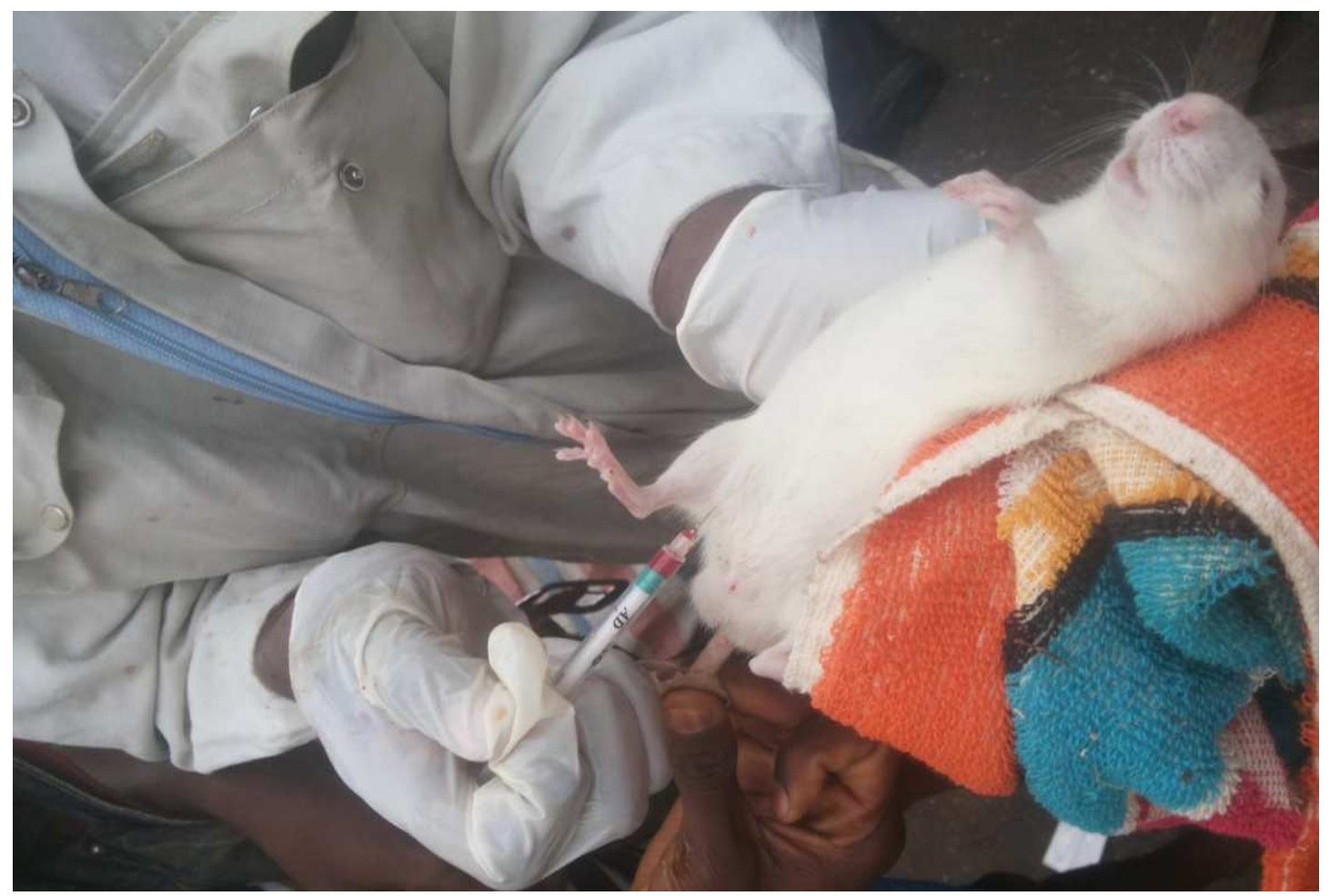

Plate 2: Albino Rat being inoculated with Camel Blood Infected with T. evansi 


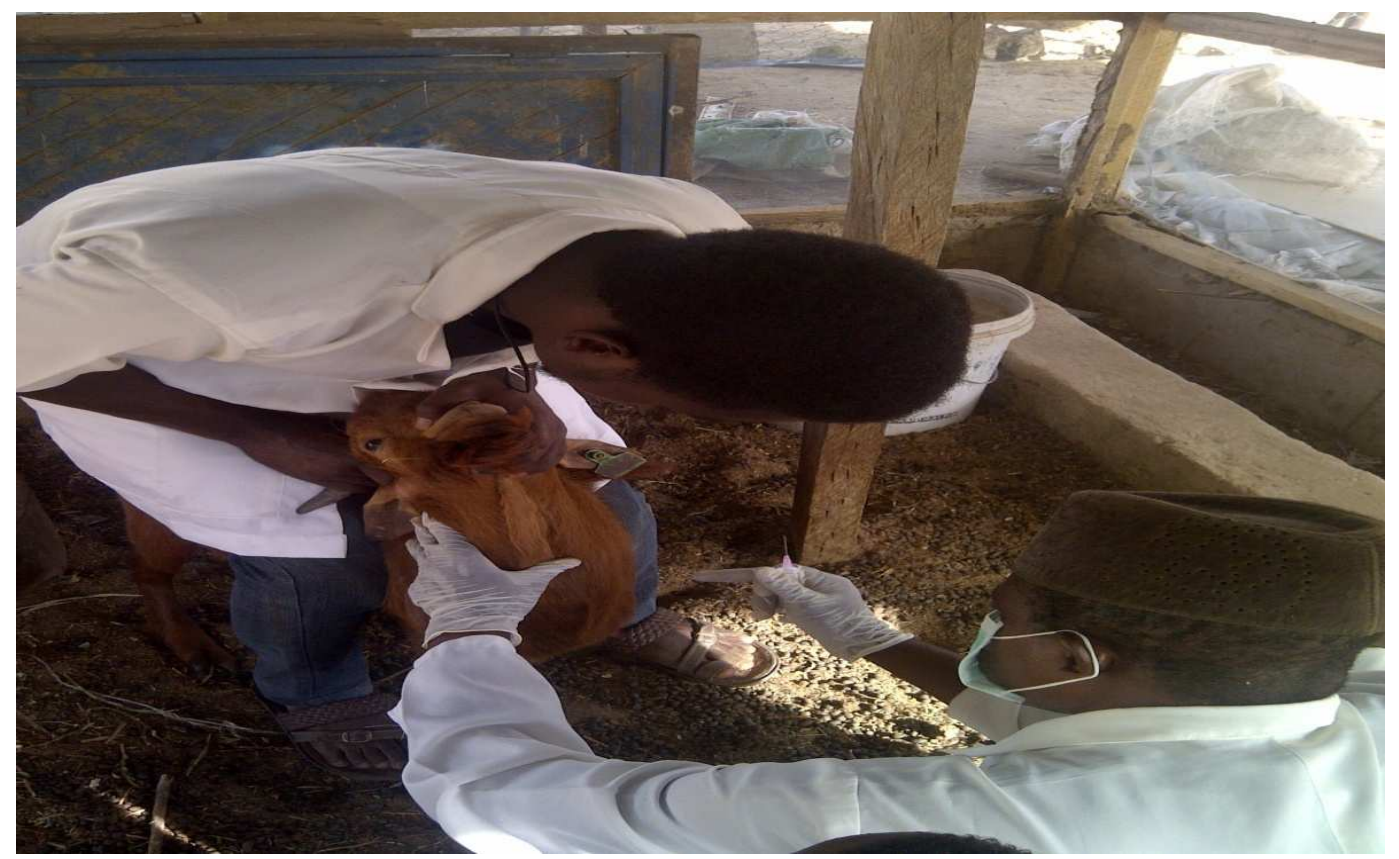

Plate3: Experimental Goats being Inoculalated with Camel Blood Infected with $T$. evansi

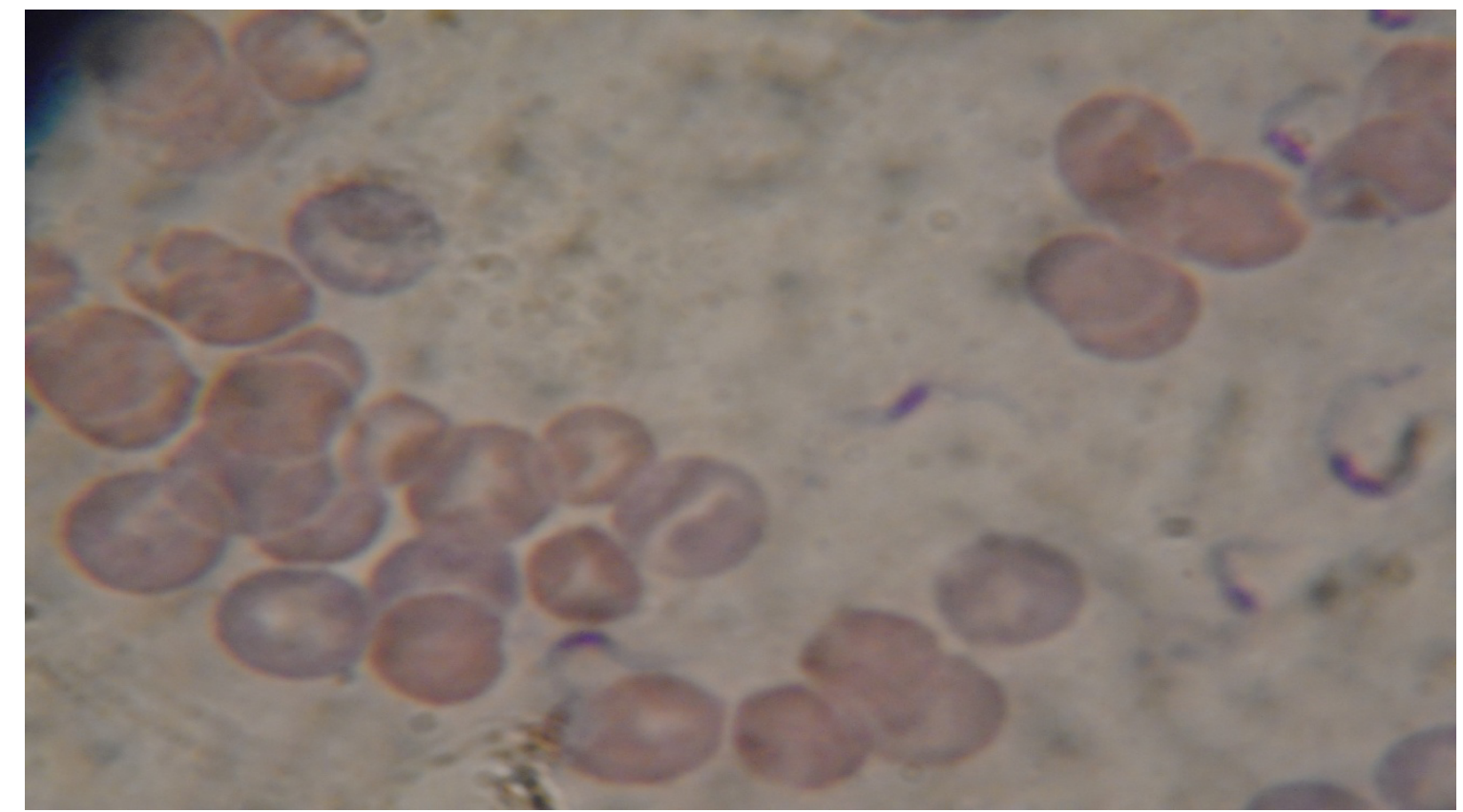

Plate 4: T. evansi Infected Blood from Dromedaries at Maigatari International Animal Market

\section{CONCLUSION}

The results from the experiment indicated that, the $T$. evansi isolate is infective to Kano brown

\section{REFERENCES}

Audu, P. A., Esievo, K.A.N., Mohammed, G. and Ajanusi, J.O. (1999).Studies on the Infectivity of an isolate of Trypanosoma evansi in Yankasa sheep. Vet. Parasitool., 86:185-190.

Cheesbrough, M. ( 2006). District LaboratoruPrctice in Tropical Conutries (2) 558- 361. goats and significantly brought changes in the levels of serum ALT and AST in the experimentally infected subjects.

Deganchew, S., Bazie, M., Terefe, G., Abeba, G., Bamy, J.D. and Goddeeris, O.M. (2015). Comparative Clinical Haematological Analysis in Young Zebu Cattle Experimentally Infected with Trypanosomavivax isolated from Tsetse Infected and Non - Tsetse Infested Areas of Northern Ethiopia. Acta Vet.Scand. 27: 24 - 31. 
Desquesnes, M., Holemuller, P., Lai, D.H., Dargantes, A., Lun, Z.R. and Jittaplapong, S. (2013). Trypanosoma evansi and Surra: A Review and Perspectives on Origin, History, distribution, Taxonomy, Morphology, Hosts and Pathogenic Effects. Bio. Med. Int., Vol. 2013. 10.1155/2013/194176.

Finangwai, H.J., Oristakwe, C.J., Joshua, P, Udoh, E.D. and Dafur, B.S. (2018). Performance and Haematological Parameter of Kano Brown Bucks Fed Diet Containing Graded Levels of Cottonseed Cake. Nig. J. Anim. Prod. 45*1): 89 - 98.

Gomez, K.A. and Gomez, A.A. (1984). Statistical Procedure for Agriculture Research, Longman Singapore.

Hoare, C.A. (1972). The Trypanosomes of Mammals. A Zoological Monograph. Oxford, Great Britain, Blackwell Scientific Publishing. P. 749.

Kadima, K.B., Gyang, E.O., Sanov, D.I. and Esievo, K.A.N. (2000). Serum Biochemical Values of Trypanosomavivax Infected Cattle and Effect of Lactose Saline Infusion. Veterinariski Archive, 70(2): 67 - 74.

Ogbeja, C.I., Lawal, I.A. and Ajanusi, A. (2011). Infectivity and Pathogenicity of Sokoto (Northern Nigeria) Isolate of Trypanosoma evansi in West Africa Dwarf Goats. International Journal of Animal and Veterinary Advances. 3(3): $117-124$.

Olafadechan, O.A. and Adebayo, O.F. (2016). Nutritional Evaluation of Ammoniated Threshed Sorghum, Tip as a Feed for Growing Goats. Tropical Health and Production. 48940: 785 - 791.

Petena, W.B. (1963). A Method of Counting Trypanosomes Using Gram lodine as Diluent, Trans Royal Soc. Rop. Med. Hyt., 57: 307.

RanjishKumasr, M., Saravanan, B.C., Yadava, S.C., Kumar R. Singh, R., Malik, T.A. and Dey, S. (2013). Neurological Trypanosomosis in Quinapyramine
Sulfate - Treated Horses - A Breach of the Blood - Brain Barrier? TropicalAnimal Health and Production. 46: 371 - 377.

Steven, L.A. and Michael, A.S. (2000). Fundamental of Veterinary Pathology. lowa State Press, $4^{\text {th }}$ edition. Blackwell Co. Ltd.

Takeet, M.I., Tagbemi, b.O., Olaniyi, M.O. and Takeet, O.V.A. (2011). Comparative Study on haematological and Plasma Biochemical Responses of Rabbits to Experiential Single and mixed Infection of Trypanosomabrucei and Trypanosomacongelense. Nigeria Veterinary Journal. Vol. 33(2): 462 474.

Teweri, A.K., Maharana, B.R., Sudan, V., Sakavanan, B.C. and Shankar, M. (2012). The Paraflagelles rod of Kinetoplastis: A Novel Therapeutic and Prophylactic Target. Integrated Research Approaches in Veterinary parasitology. Pp. 278 - 284.

Teweri, A.K., Saravanua, B.C., Sudan, V., Maharana, B.R. and Sudhakar, N.R. (2013). Trypanosomosis Caused by $T$. evansi. An insight. Livestock Management Product Technology and Health. Pp. 409 - 411.

TNFD: The Third National Fadama Development Project.

Urquahart, G.M., Amow, J., Dunkan, J.L., Dunn, A.M. and Jennings, F.W. (1996). Veterinary parasitology. $2^{\text {nd }}$ edition. U.K.: Blackwell Sciences. Pp. 103 - 113.

Yadav, S.C., Jaideep, K., Gupta, A.K., Derome, A., Probhat, K., Rejender, K., Kanika, T. and Ritesa, K. (2016). Parasitological, Biological and Clinical Observation in Ponies Experimentally Infected with Trypanosoma evansi. Journal of Experimental Biology and Agricultural Sciences: 4/EPI: 144 - 150.

Youssif, F.N. (2000). Pharmacological Studies on $T$. evansi Infected Goats. Mvsc, Khartoum, University of Khartoum. 